\title{
Growth and viability of Liaoning Cashmere goat hair follicles during the annual hair follicle cycle
}

\author{
Q.L. Zhang ${ }^{1}$, J.P. Li ${ }^{2}$, Y. Chen ${ }^{2}$, Q. Chang ${ }^{2}$, Y.M. Li ${ }^{1}$, J.Y. Yao ${ }^{2}$, \\ H.Z. Jiang ${ }^{2}$, Z.H. Zhao ${ }^{1}$ and D. Guo ${ }^{3}$ \\ ${ }^{1}$ College of Animal Science and Veterinary Medicine, Jilin University, \\ Changchun, China \\ ${ }^{2}$ College of Animal Science and Technology, Jilin Agricultural University, \\ Changchun, China \\ ${ }^{3}$ Liaoning Cashmere Goat Breeding Center, Liaoyang, China \\ Corresponding authors: H.Z. Jiang / Z.H. Zhao \\ E-mail: jianghz6806@126.com / zhzhao@jlu.edu.cn
}

Genet. Mol. Res. 13 (2): 4433-4443 (2014)

Received April 16, 2013

Accepted October 30, 2013

Published June 16, 2014

DOI http://dx.doi.org/10.4238/2014.June.16.2

\begin{abstract}
Here, we studied hair follicle development of Liaoning Cashmere goats. Every month for 1 year, skin samples were collected from five 1.5-year-old female goats, and made into paraffin sections. A number of parameters were measured of primary and secondary hair follicles via microscopic observation including follicle depth, hair bulb width, dermis and epidermis thickness, changes in follicle activity, and histology. The results showed the presence of three phases in the annual hair cycle: anagen, catagen, and telogen. Primary and secondary hair follicle depth varied across the months; however, no significant difference was obtained between adjacent months $(\mathrm{P}>0.05)$. Primary hair follicles had a bigger hair bulb width compared to secondary hair follicles; however, this difference declined during hair follicle developed in anagen. As hair follicle growth slowed, the hair bulb broadened, and hair root depth became shallower. During the entire hair cycle, hair
\end{abstract}


follicle depth and dermis thickness were positively correlated; however, this relationship was not significant $(\mathrm{P}>0.05)$ for primary and secondary hair follicle density and the ratio of secondary hair follicle density and primary hair follicle density (S/P ratio). In addition, new and old primary hair follicles coexisted with secondary hair follicles. Finally, secondary hair follicles had a higher activity rate compared to primary hair follicle in adult Liaoning Cashmere goats in certain months.

Key words: Adult Liaoning Cashmere goats; Hair follicle viability; Primary hair follicle; Secondary hair follicle; Hair follicle cycle

\section{INTRODUCTION}

Hair is a primary characteristic of mammals, and has a large number of functions, such as physical protection, thermoregulation, sensory, and tactile activity. The hair follicle (HF) is the structure that is responsible for the production of hair. It consists of many concentric layers, including the outer root sheath (ORS), inner root sheath (IRS), and hair shaft (HS) (Alonso and Fuchs, 2006; Fuchs, 2007). HF develops during fetal skin development and is closely associated with ectodermal-mesodermal interactions (Schmidt-Ullrich and Paus, 2005; Fuchs, 2007; Schneider et al., 2009). Ectodermal hair follicle stem cells (HFSC) develop into all of the epithelial components of HF, including the sebaceous gland (SG) and apocrine sweat gland, whereas mesoderm-derived cells develop into the follicular dermal papilla (DP) and connective tissue sheath. Furthermore, neural crest-derived melanocyte progenitors (melanoblasts) develop into the HF pigmentary unit (Fuchs, 2008; Fuchs and Horsley, 2008). After birth, mature and actively growing HF eventually become anchored in the subcutis, and periodically regenerate by spontaneously undergoing repetitive cycles of anagen (growth), catagen (cessation), and telogen (rest) (Chase, 1954; Alonso and Fuchs, 2006; Fuchs, 2007; Wang et al., 2012).

China is the largest producer of Cashmere fiber worldwide, accounting for $50 \%$ of the world's total production (Bai et al., 2006). Goat breeds in China have been replaced by Inner Mongolian White Cashmere goat and Liaoning White Cashmere goat in recent years (Zhang et al., 2007). The new breed of Liaoning Cashmere goat is a special genetic resource in China. The highest recorded cashmere yield of adult male and female adult Liaoning Cashmere goat is $1,800 \mathrm{~g}$ and $845 \mathrm{~g}$, respectively (Jin et al., 2006b). Because of the high yield and good quality of Cashmere, the Liaoning Cashmere goat has already generated considerable economic benefits to local farmers. However, because hair growth in mammals is cyclical, there is seasonal variation in production. For instance, it has been reported that Cashmere yield ranges from $3 \%$ in the summer to $25 \%$ in the winter for animals of up to 2-years old (Ryder, 1987; Ibraheem et al., 1993). However, detailed knowledge about various parameters of the hair follicle cycle remains limited; information is required about the initiation of primary hair follicle (PHF) and secondary hair follicle (SHF), in addition to the particular features of adult HF and the timing of cycling from active to inactive states in different breeds.

HF development has been used as an ideal model to study organ morphogenesis, and has been extensively investigated at the molecular, cellular, and genetic level (Fuchs, 2007; Palmer et al., 2008; Schouwey and Beermann, 2008); however, these studies mainly focus 
on mice. The hairy coat of Liaoning Cashmere goats is primarily composed of a double coat structure. The economically viable part of the fleece is produced by SHF, with this part being finer when the double coat structure is present. However, researchers have mainly focused on studying the effects of copper and molybdenum (Zhang et al., 2011) or iodine and selenium (Qin et al., 2011) on fiber production. Other studies have focused on the characterization of the growth hormone receptor gene (GHR) and genetic variation (Bai et al., 2011) or the correlation of blood protein polymorphism with economic traits (Jin et al., 2006a). The current study focused on investigating the biology and annual cycle of HF development in relation to the structure of the wool fiber, to improve both the efficiency of growing Liaoning Cashmere goat wool and its quality as an economically important product of China.

\section{MATERIAL AND METHODS}

\section{Animals}

In November 2009, five 1.5-year-old adult female (not pregnant) Liaoning Cashmere goats were selected randomly from the herd of the Liaoning provincial Cashmere Goat Breeding CenterBaicheng, Jiling Province, China $\left(45.38^{\circ} \mathrm{N}, 122.50^{\circ} \mathrm{E}\right)$.

\section{Samples and treatments}

\section{Follicle activity}

Skin samples were collected by biopsy punch (1-cm diameter) once a month on the right side of the scapula. All the 5 animals were sampled on the 15 th of every month. Skin samples were fixed in $4 \%$ paraformaldehyde, and then processed through graded concentrations of ethanol, and embedded in paraffin wax (YD-6D), with the epidermal surface being uppermost. The $8-\mu \mathrm{m}$ transverse sections and longitudinal sections of embedded skin were serially cut on a rotary microtome (Leica RM 2235, Germany), stained with an adapted Sacpic stain, examined microscopically (PXS-1020, Shanghai, China; Leica DM 1000, Beijing, China), and photos were taken (Pixera pro150ES, USA). The follicle depth all PHF and SHF was measured under the microscope. The thickness of the epidermis and dermis was measured from the longitudinal sections by the Image-Pro Plus software. PHF and SHF activity was assessed by the staining characteristics of the inner-root sheath (IRS), with red colored IRS indicating activity, whereby the activity rate of $\mathrm{HF}=$ the number of HF with activity/total HF.

\section{Statistical analyses}

The average and standard deviations of relevant data were statistically analyzed as a completely randomized design using the SPSS Statistics 18 (SPSS 18.0) software. Analysis of variance of a single factor was statistically analyzed using the Duncan method, and Pearson product-moment coefficient was calculated and tested by correlation procedure in SPSS with corresponding options. Differences in the variables means were determined by the least significant difference when the $\mathrm{F}$ value was significant $(\mathrm{P}<0.05)$. 


\section{RESULTS}

\section{Light microscopy}

All slices were observed by light microscope (PXS-1020, Shanghai, China; Leica DM 1000, Beijing, China) (Figure 1). During the HF cycle, the original PHF and the new PHF coexist in the same canal; and 2 or more SHF coexist in a single sheath. After one HF cycle, old PHF withered and remained near the epidermis. The old PHF were then surrounded with new PHF in one connective tissue sheath, with the new PHF being bigger than the old one (Figure 1A). This phenomenon was recorded throughout the year. In addition, the diameter ratios of new follicle and old follicles changed in different months. The diameter of the new and old PHF were almost equal when new PHF entered the growth phase (Figure 1B).
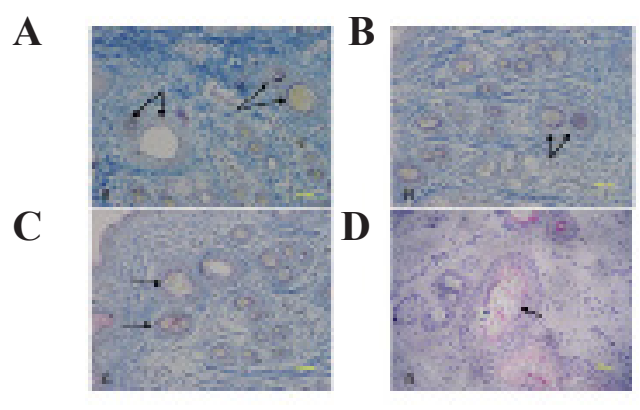

Figure 1. Morphologic image of primary hair follicle (PHF) (A and B) and secondary hair follicle (C and D) of Liaoning Cashmere goats during HF cycle. A. B. Transverse section slice of PHF in May and November, respectively; the arrow indicated neonatal PHF (right) and old one (left). A. Diameter of neonatal PHF and old one were almost equal when the new primary follicle entered into the growth period. B. C. D. Transverse section slice of SHF; the arrow indicated that more than two SHF were bundled by a HF sheath. C. and D. Bars $=100 \mu \mathrm{m}$.

With respect to SHF, 2 or more SHF occurred in combination in the connective tissue sheath, ORS, and IRS (Figure 1C), with up to 10 SHF being combined (Figure 1D). These hairs extended to the epidermis and emerged at the skin surface from the same orifice.

\section{HF depth and hair bulb width}

The results of HF depth and hair bulb width measurements of vertical plane are presented in Table 1.

The results showed that PHF and SHF depth changed during course of the year; however, HF depth was not significantly different in adjacent months $(\mathrm{P}>0.05)$. However, PHF depth was significantly different between February and April, and August and September $(\mathrm{P}<$ 0.05). PHF depth was the deepest in August $(1867.19 \pm 246.64 \mu \mathrm{m})$ and the shallowest in February $(1336.82 \pm 123.19 \mu \mathrm{m})$. SHF depth was significantly different between May and August $(\mathrm{P}<0.05)$. SHF depth was the deepest in August $(1382.84 \pm 104.83 \mu \mathrm{m})$ and the shallowest in May $(1020.41 \pm 183.62 \mu \mathrm{m})$.

Primary hair bulb width changed during the course of the year; however, this parameter was not significantly different in adjacent months $(\mathrm{P}>0.05)$, except for October and November $(\mathrm{P}<0.05)$. Maximum primary hair bulb width was recorded in October $(215.68 \pm 34.54 \mu \mathrm{m})$, 
while the minimum width was recorded in November $(143.93 \pm 22.31 \mu \mathrm{m})$. Hair bulb width was significantly different between January and October, and November and December $(\mathrm{P}<0.05)$. A significant change in secondary bulb width was recorded between April and May $(\mathrm{P}<0.05)$, with no significance between any other months $(\mathrm{P}>0.05)$. The largest hair bulbs width was recorded in May $(96.37 \pm 12.56 \mu \mathrm{m})$, while smallest was recorded in February $(69.81 \pm 12.91 \mu \mathrm{m})$.

Table 1. HF depth and hair bulbs width of adult Liaoning Cashmere goats in different months (means \pm SD).

\begin{tabular}{ccccc}
\hline \multirow{2}{*}{ Month } & \multicolumn{2}{c}{ HF depth $(\mu \mathrm{m})$} & \multicolumn{2}{c}{ Hair bulbs width $(\mu \mathrm{m})$} \\
\cline { 2 - 4 } & \multicolumn{1}{c}{ PHF } & SHF & PHF & SHF \\
\hline 1 & $1566.77 \pm 85.57^{\mathrm{ab}}$ & $1225.84 \pm 153.66^{\mathrm{ab}}$ & $214.54 \pm 27.09^{\mathrm{a}}$ & $73.43 \pm 9.04^{\mathrm{a}}$ \\
2 & $1336.82 \pm 123.19^{\mathrm{a}}$ & $1117.43 \pm 188.17^{\mathrm{ab}}$ & $192.33 \pm 12.62^{\mathrm{abc}}$ & $69.81 \pm 12.91^{\mathrm{a}}$ \\
3 & $1696.03 \pm 349.33^{\mathrm{ab}}$ & $1158.64 \pm 200.77^{\mathrm{ab}}$ & $189.00 \pm 27.50^{\mathrm{abc}}$ & $73.29 \pm 6.22^{\mathrm{a}}$ \\
4 & $1844.33 \pm 42.01^{\mathrm{b}}$ & $1174.50 \pm 234.83^{\mathrm{ab}}$ & $195.80 \pm 23.05^{\mathrm{abc}}$ & $73.40 \pm 8.79^{\mathrm{a}}$ \\
5 & $1582.69 \pm 100.13^{\mathrm{ab}}$ & $1020.41 \pm 183.62^{\mathrm{a}}$ & $202.28 \pm 11.44^{\mathrm{ab}}$ & $96.37 \pm 12.56^{\mathrm{b}}$ \\
6 & $1662.51 \pm 156.61^{\mathrm{ab}}$ & $1205.19 \pm 177.29^{\mathrm{ab}}$ & $07.97 \pm 52.02^{\mathrm{ab}}$ & $84.16 \pm 1.56^{\mathrm{ab}}$ \\
7 & $1791.14 \pm 298.26^{\mathrm{ab}}$ & $1270.78 \pm 183.15^{\mathrm{ab}}$ & $205.30 \pm 36.58^{\mathrm{ab}}$ & $87.39 \pm 7.22^{\mathrm{ab}}$ \\
8 & $1867.19 \pm 246.64^{\mathrm{b}}$ & $1382.84 \pm 104.83^{\mathrm{b}}$ & $176.17 \pm 23.02^{\mathrm{abc}}$ & $72.60 \pm 12.90^{\mathrm{a}}$ \\
9 & $1854.69 \pm 221.22^{\mathrm{b}}$ & $1308.093 \pm 41.63^{\mathrm{ab}}$ & $171.75 \pm 10.37^{\mathrm{abc}}$ & $75.70 \pm 8.17^{\mathrm{a}}$ \\
10 & $1757.51 \pm 448.58^{\mathrm{ab}}$ & $1125.56 \pm 172.14^{\mathrm{ab}}$ & $215.68 \pm 34.54^{\mathrm{a}}$ & $72.35 \pm 7.19^{\mathrm{a}}$ \\
12 & $1653.62 \pm 298.03^{\mathrm{ab}}$ & $1122.31 \pm 260.91^{\mathrm{ab}}$ & $143.93 \pm 22.31^{\mathrm{c}}$ & $78.22 \pm 12.55^{\mathrm{ab}}$ \\
\hline
\end{tabular}

$\mathrm{HF}=$ hair follicle; $\mathrm{PHF}=$ primary hair follicle; SHF $=$ secondary hair follicle. Different letter showed that the difference was significant in the same column $(\mathrm{P}<0.05)$, the equal letter showed that the difference was not significant in the same column $(\mathrm{P}>0.05)$.

\section{Skin thickness}

The thickness of the epidermis and dermis on the vertical plane for each month are presented in Table 2, along with the ratio of the dermis to epidermis.

Table 2. Skin's thickness of adult Liaoning Cashmere goats in different months (means \pm SD).

\begin{tabular}{|c|c|c|c|}
\hline Months & Thickness of epidermis $(\mu \mathrm{m})$ & Thickness of dermis $(\mu \mathrm{m})$ & Ratio of dermis to epidermis \\
\hline 1 & $31.19 \pm 3.35^{\mathrm{a}}$ & $1249.19 \pm 60.17^{\mathrm{a}}$ & $41.35 \pm 6.37^{\mathrm{a}}$ \\
\hline 2 & $30.14 \pm 2.52^{\mathrm{a}}$ & $1230.11 \pm 224.82^{\mathrm{ab}}$ & $40.43 \pm 4.86^{\mathrm{a}}$ \\
\hline 3 & $31.11 \pm 2.93^{\mathrm{a}}$ & $1357.84 \pm 132.85^{\text {ac }}$ & $45.25 \pm 8.73^{\mathrm{ab}}$ \\
\hline 4 & $34.23 \pm 2.94^{\mathrm{ab}}$ & $1411.69 \pm 81.39^{\mathrm{bcd}}$ & $41.65 \pm 3.11^{\mathrm{a}}$ \\
\hline 5 & $40.03 \pm 3.36^{\mathrm{b}}$ & $1147.88 \pm 42.89^{b}$ & $28.98 \pm 2.10^{\mathrm{c}}$ \\
\hline 6 & $39.56 \pm 4.55^{\mathrm{b}}$ & $1322.08 \pm 134.33^{\mathrm{ad}}$ & $33.97 \pm 4.04^{\mathrm{a}}$ \\
\hline 7 & $34.98 \pm 5.01^{\mathrm{ab}}$ & $1531.08 \pm 258.13^{\text {ade }}$ & $48.13 \pm 5.59^{\mathrm{ab}}$ \\
\hline 8 & $36.60 \pm 7.84^{\mathrm{ab}}$ & $1596.29 \pm 131.44^{\text {bce }}$ & $47.15 \pm 9.85^{\mathrm{ab}}$ \\
\hline 9 & $45.28 \pm 6.71^{\mathrm{b}}$ & $1581.20 \pm 158.86^{\text {bce }}$ & $36.19 \pm 5.00^{\mathrm{a}}$ \\
\hline 10 & $32.38 \pm 1.44^{\mathrm{a}}$ & $1424.99 \pm 124.59^{\text {ade }}$ & $44.54 \pm 6.03^{\mathrm{ab}}$ \\
\hline 11 & $39.54 \pm 2.62^{b}$ & $1335.64 \pm 163.12^{\text {ad }}$ & $34.28 \pm 5.15^{\mathrm{ac}}$ \\
\hline 12 & $32.23 \pm 2.04^{\mathrm{a}}$ & $1328.72 \pm 160.40^{\mathrm{ad}}$ & $41.87 \pm 6.59^{\mathrm{a}}$ \\
\hline
\end{tabular}

Different letter represented that the difference was significant in the same column $(\mathrm{P}<0.05)$, the equal letter represented that the difference was not significant in the same column $(\mathrm{P}>0.05)$.

The epidermis was very thin from January to April, and the thickness of the epidermis began to increase from April, but this change was not significant $(P>0.05)$. The thickness of the epidermis noticeably increased in May, and was significantly different compared to January, February, and March $(\mathrm{P}<0.05)$. The epidermal thickness reached a maximum in September $(45.28 \pm 6.71 \mu \mathrm{m})(\mathrm{P}>0.05)$. The epidermal thickness began to fluctuate substantially from October to December. 
The thickness of the dermis increased from January to April, but there was no significant difference between these months $(\mathrm{P}>0.05)$. Dermal thickness noticeably decreased to its thinnest levels of the whole year in May $(1147.88 \pm 42.89 \mu \mathrm{m})(\mathrm{P}<0.05)$. Dermal thickness began to noticeably increase in June $(\mathrm{P}<0.05)$ and remained at a similar level for several months $(\mathrm{P}>0.05)$. The maximum dermal thickness was recorded in August (1596.29 $\pm 131.44 \mu \mathrm{m})$, after which it decreased.

The ratio of the dermis to epidermis fluctuated from January to April, but was not significantly different $(\mathrm{P}>0.05)$. The ratio significantly decreased and reached the minimum for the entire year in May $(\mathrm{P}<0.05)$. Then it significantly increased $(\mathrm{P}<0.05)$ and reached the maximum for the year in July $(48.13 \pm 5.59 \mu \mathrm{m})$. From August, the ratio began to decrease, but was not significantly different $(\mathrm{P}>0.05)$. Then the ratio began to fluctuate in subsequent months, but was not significantly different $(\mathrm{P}>0.05)$.

\section{HF density and $\mathrm{S} / \mathrm{P}$ ratio}

The amount of PHF and SHF in the transverse section of one view in different months is presented in Table 3, along with HF density and ratio $(\mathrm{S} / \mathrm{P})$. Despite HF density fluctuating across months, there was no significant difference $(\mathrm{P}>0.05)$. In addition, the $\mathrm{S} / \mathrm{P}$ ratio was not significantly different across months $(\mathrm{P}>0.05)$.

Table 3. Density of HFs and S/P of adult Liaoning Cashmere goats in different months (means $\pm \mathrm{SD}$ ).

\begin{tabular}{|c|c|c|c|}
\hline Months & Density of PHF $\left(\cdot \mathrm{mm}^{-2}\right)$ & Density of SHF $\left(\cdot \mathrm{mm}^{-2}\right)$ & Ratio of S/P \\
\hline 1 & $3.01 \pm 0.45^{\mathrm{a}}$ & $41.63 \pm 7.15^{\mathrm{a}}$ & $13.83 \pm 2.37^{\mathrm{a}}$ \\
\hline 2 & $3.11 \pm 0.31^{\mathrm{a}}$ & $34.36 \pm 3.39^{\mathrm{a}}$ & $11.42 \pm 1.12^{\mathrm{a}}$ \\
\hline 3 & $3.26 \pm 0.33^{\mathrm{a}}$ & $38.12 \pm 1.89^{\mathrm{a}}$ & $11.82 \pm 1.53^{\mathrm{a}}$ \\
\hline 4 & $3.29 \pm 0.29^{\mathrm{a}}$ & $41.13 \pm 10.27^{\mathrm{a}}$ & $12.62 \pm 1.46^{\mathrm{a}}$ \\
\hline 5 & $2.91 \pm 0.22^{\mathrm{a}}$ & $33.86 \pm 7.82^{\mathrm{a}}$ & $11.71 \pm 2.30^{\mathrm{a}}$ \\
\hline 6 & $3.05 \pm 0.41^{\mathrm{a}}$ & $41.38 \pm 4.75^{\mathrm{a}}$ & $13.75 \pm 0.25^{\mathrm{a}}$ \\
\hline 7 & $3.13 \pm 0.24^{\mathrm{a}}$ & $39.38 \pm 7.53^{\mathrm{a}}$ & $12.51 \pm 1.76^{\mathrm{a}}$ \\
\hline 8 & $3.08 \pm 0.47^{\mathrm{a}}$ & $35.11 \pm 3.39^{\mathrm{a}}$ & $11.67 \pm 1.12^{\mathrm{a}}$ \\
\hline 9 & $2.97 \pm 0.29^{\mathrm{a}}$ & $38.37 \pm 3.91^{\mathrm{a}}$ & $13.28 \pm 0.37^{\mathrm{a}}$ \\
\hline 10 & $3.09 \pm 0.21^{\mathrm{a}}$ & $36.11 \pm 9.24^{\mathrm{a}}$ & $12.05 \pm 1.16^{\mathrm{a}}$ \\
\hline 11 & $3.04 \pm 0.36^{\mathrm{a}}$ & $36.18 \pm 6.33^{\mathrm{a}}$ & $12.00 \pm 0.25^{\mathrm{a}}$ \\
\hline 12 & $2.89 \pm 0.38^{\mathrm{a}}$ & $40.38 \pm 4.41^{\mathrm{a}}$ & $13.98 \pm 0.53^{\mathrm{a}}$ \\
\hline
\end{tabular}

\section{HF activity}

The activity of PHF and SHF during the HF life-cycle phases was observed under the light microscope (Figure 2A-H), with the activity rates being presented in Table 4. Figure 3 shows the trends in variation of these parameters.

The curve representing the change in the activity of PHF was "V" shaped. Specifically, maximum activity was recorded in January $(93.21 \pm 2.43 \%)$, then significantly decreased $(\mathrm{P}<0.05)$ in February and March. Activity was just $20 \%$ that of January in March and April, and then further decreased to the annual minimum in May $(\mathrm{P}<0.05)(13.56 \pm 2.22 \%)$, with just $13.5 \%$ HF activity compared to January. Then, the activity significantly increased in June, July, and August $(\mathrm{P}<0.05)$, and remained high in the following months $(\mathrm{P}>0.05)$. There was no significant difference in activity between December and January $(\mathrm{P}>0.05)$. 
There was no significant change in SHF activity between January and February (P > $0.05)$. SHF activity significantly decreased from February, and reached the annual minimum in April (23.47 $\pm 3.44 \%)$. Then, there was a gradual increase in activity in May and June (P $>0.05)$. Activity significantly increased in July and August $(\mathrm{P}<0.05)$, with high levels being maintained until January.

Table 4. Activity rate of HF of adult Liaoning Cashmere goats in different months (means $\pm \mathrm{SD}$ ).

\begin{tabular}{lrr}
\hline Months & Activity rate of PHF (\%) & Activity rate of SHF $(\%)$ \\
\hline 1 & $93.21 \pm 2.43^{\mathrm{a}}$ & $96.44 \pm 6.63^{\mathrm{a}}$ \\
2 & $72.88 \pm 5.57^{\mathrm{b}}$ & $93.19 \pm 4.29^{\mathrm{a}}$ \\
3 & $24.28 \pm 3.39^{\mathrm{c}}$ & $58.35 \pm 5.52^{\mathrm{b}}$ \\
4 & $20.09 \pm 1.98^{\mathrm{c}}$ & $23.47 \pm 3.44^{\mathrm{c}}$ \\
5 & $13.56 \pm 2.22^{\mathrm{d}}$ & $32.59 \pm 1.09^{\mathrm{cd}}$ \\
6 & $49.72 \pm 3.57^{\mathrm{e}}$ & $50.37 \pm 4.99^{\mathrm{b}}$ \\
7 & $62.33 \pm 6.49^{\mathrm{f}}$ & $63.68 \pm 3.93^{\mathrm{b}}$ \\
8 & $75.10 \pm 4.09^{\mathrm{b}}$ & $88.09 \pm 5.33^{\mathrm{a}}$ \\
9 & $72.83 \pm 2.47^{\mathrm{b}}$ & $84.62 \pm 6.61^{\mathrm{a}}$ \\
10 & $79.99 \pm 5.83^{\mathrm{ab}}$ & $93.92 \pm 7.32^{\mathrm{a}}$ \\
12 & $82.19 \pm 5.44^{\mathrm{a}}$ & $92.73 \pm 8.47^{\mathrm{a}}$ \\
\hline
\end{tabular}

$\mathrm{HF}=$ hair follicle; PHF = primary hair follicle; SHF = secondary hair follicle. Different letter showed that the difference was significant in the same column $(\mathrm{P}<0.05)$, the equal letter showed that the difference was not significant in the same column $(\mathrm{P}>0.05)$.

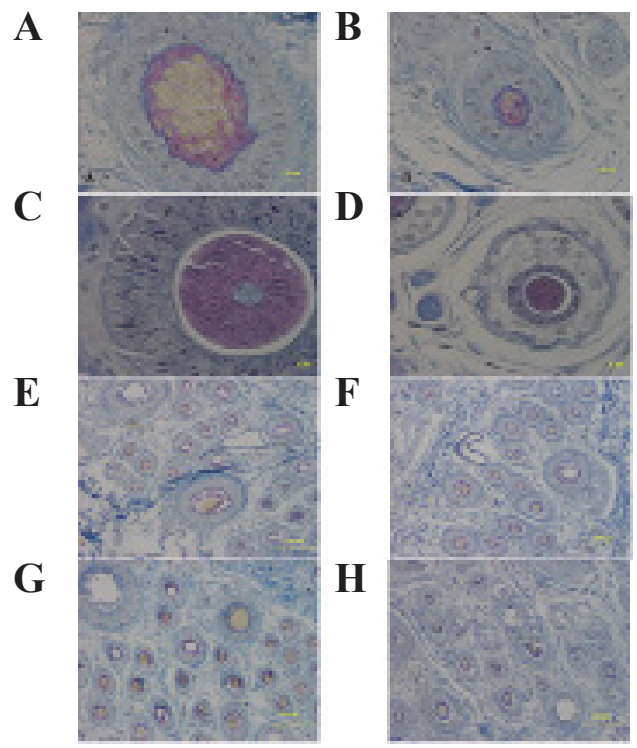

Figure 2. Activity state of hair follicle of adult Liaoning Cashmere goats in different stage. A. Primary hair follicle (PHF) in the period of dormancy (resting phase) indicated that the demarcation line of inner root sheath (IRS) and outer root sheath was not obvious, and the shape was not irregular; B. secondary hair follicle (SHF) in the period of dormancy (resting phase), the feature was the same as PHF; C. incrassate IRS emerged punctiform structure and sheet structure, which were red; and the cortex of hair shaft was red, but the medulla of hair shaft of PHF did not dye to red; D. SHF in the period of anagen (growth phase). Bars on A-D $=10 \mu \mathrm{m}$. E. F. Many PHF and SHF were activated. Thick arrow represented PHF; the thin arrow indicated the SHF, red IRS was clearly observed obviously; G. Inactive PHF (thick arrow) and active SHF (thin arrow); H. inactive PHF (thick arrow) and SHF (thin arrow), but some of SHF were active, and some were inactive, in which IRS were not red; and there were many SHF in the period of dormancy (resting phase); bars on $\mathbf{E}-\mathbf{H}=100 \mu \mathrm{m}$. 


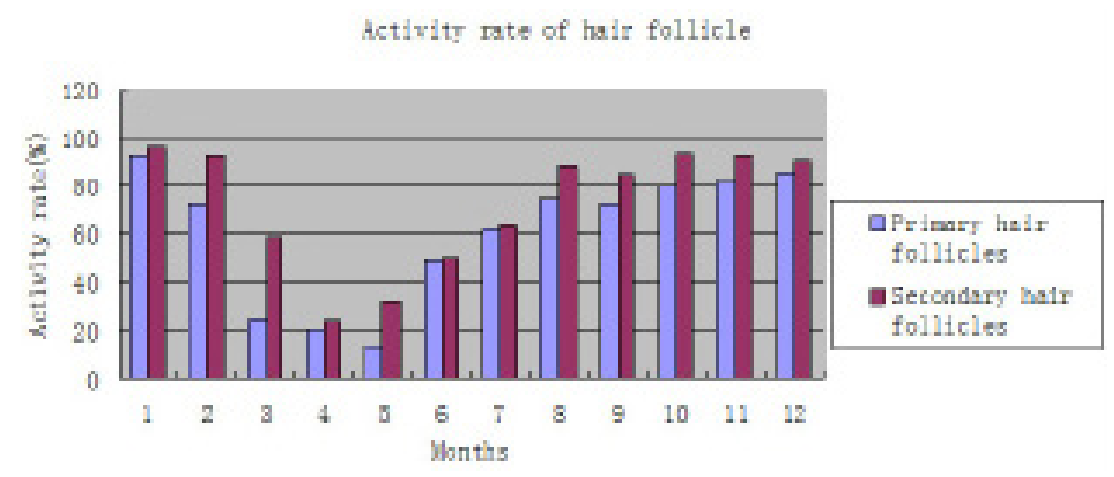

Figure 3. Activity rate of hair follicle of adult Liaoning Cashmere goats in different months.

\section{DISCUSSION}

HF undergoes regular cycles of involution and regeneration throughout the entire lifetime of a mammal. Initially, HF develops from the embryonic epidermis as an epithelial finger. This cyclic regeneration is assumed to require many cellular signals that are also integral to other morphogenetic and regenerating systems. The epithelium and mesenchyme communicate in all of these systems (Stenn and Paus, 2001).

The placode is the earliest formed morphological structure during HF development. It is formed through focal epithelial proliferation, which is induced by signals arising from the underlying mesenchyme, termed the "first dermal signal" (Wang et al., 2012). Once a HF enters the regression phase, the lower, cycling portion of the HF is degraded. This process brings the DP into close proximity of the placode bulge, where the HFSC resides. The molecular interaction between the HFSC and DP is essential to form a new HF. Anagen (growth phase) is only imitated when a critical concentration of hair growth activating signals is reached and a new hair is regrown (Schneider et al., 2009).

In the study, the hair follicle cycle followed the three known phases: anagen (growth), catagen (cessation), and telogen (rest). The histomorphology of the 60 samples (one per month) from each animal showed that the HF and dermis characteristics varied across the months, with HF development being synchronized. HF development entered catagen from January, during which HF depth and dermis thickness declined until May. Then HF development entered telogen from June onwards, during which HF depth and dermis thickness increased until August. Finally, HF development entered anagen from September, during which HF depth and dermis thickness decreased until January. During the whole HF cycling, HF depth and dermis thickness were positively correlated. Catagen was the longest of the 3 phases in Liaoning Cashmere goats. In contrast, Anagen was the longest phase recorded in mice (Schneider et al., 2009). This difference might be related to selective traits for economic benefit and environmental characteristics.

Previous studies of mice indicated that old hair shaft (club hair) normally remains in the canal, even when the new hair emerges through the same orifice, with the telogen club hair potentially resting in its socket for several cycles. This phenomenon leads to the bulging of the ORS around the club (Stenn and Paus, 2001). In this study, we also observed the coexistence phenomenon of old and new PHF during the HF cycle. After one HF cycle, the old PHF with- 
ered and remained near the epidermis, surrounded by one connective tissue sheath containing the new PHF. This phenomenon was observed throughout the entire year. There were also often 2 or more SHF in a single connective tissue sheaf, ORS, and IRS (combination phenomenon), along with extending to the epidermis. The SHF were wrapped in a large structure of 3 layers, which resulted in an increase of hair density.

Previous studies indicated that SHF activity continues for 10 to 11 months in Inner Mongolia Cashmere goats. Even during the catagen phase, SHF continues to grow slowly. HF stops active growth during the telogen phase. In addition, SHF growth increased from May to August, with the highest activity from July to October. SHF activity began to significantly decrease after December, and reached catagen. In our experiment, we found that PHF and SHF activity presented a similar trend during the HF cycle. Both HF types presented a "V" shaped activity curve, with the lowest activity being recorded in May. In all the 3 phases, SHF activity was consistently higher compared to PHF. The lowest SHF activity was recorded in April $(23.47 \pm 3.44 \%)$, and then gradually increased in May and June $(\mathrm{P}>0.05)$. Then, there was a significant increase in activity during July and August $(\mathrm{P}<0.05)$, with high levels being maintained in the following months (representing anagen). Overall, the lowest HF activity, HF depth, HF density, and dermal thickness were recorded in May. This result indicates that these 3 parameters are positively correlated.

Previous studies have reported that when HF enters catogen there is a reduction in HF activity, the hairbulb broadens, and the hair root depth becomes shallower (Paus et al., 1999). In our study, we recorded the lowest SHF activity during April and May; however, hairbulb width was the greatest at this point, and only began to decline when the HF entered anagen. Other studies reported vigorous HF activity from July to November in Liaoning Cashmere goats, with the anagen (growth) phase lasting 9 months (Li et al., 2005). Other studies reported that the epidermis stratum basale cell begins rooting in March, with SHF starting to reconstruct at the same time. In these previous studies, HF entered anagen from August to September, and tended to enter catagen in December. The telagen phase lasted from February to March. However, in the current study, the vigorous HF activity phase of Liaoning Cashmere goats was recorded from August to December. These differences might be due to the influences of different climatic factors. From about the autumn equinox, PHF and SHF entered the active anagen phase, and remained active until spring, with the guard hairs of the outer coat and undercoat being grown to provide a thick winter coat (Gebbie et al., 1999). These temporal changes are associated with an increase in prolactin concentrations during spring, causing the reactivation of HF (anagen) and the moulting of the winter coat. Regrowth in secondary follicles during autumn coincides with decreasing prolactin concentrations, and re-establishes the fine undercoat. While the follicle population is determined at birth, the length of the follicles alters during the growth cycle. In skin sections parallel to the skin surface at the midlevel of the SGs, the ratio of secondary to tertiary primary follicles indicated the development of the Cashmere undercoat. At this level, the S/P ratio was typically at a maximum during autumn and winter and at a minimum during mid-summer. However, in our experiment, $\mathrm{S} / \mathrm{P}$ ratios were not significantly different across the year $(\mathrm{P}>0.05)$.

At the end of the catogen phase, the HF of mice enters a phase of relative quiescence (telogen), with the first part of the telogen phase lasting several days, and the second part of the telogen phase lasting more than 3 weeks. The greater length of each subsequent telogen phase in each HF cycle causes the HF cycle to decelerate considerably in aging animals (Plikus et 
al., 2008). In contrast, in humans, fetal HF cycling becomes asynchronous after birth, as each HF cycle follows a separate mosaic cycling pattern (Paus et al., 2004; Cotsarelis, 2006). In our experiment of Liaoning Cashmere goats, large amounts of HF were active, so that it can produce hair during the months of lowest HF activity.

\section{ACKNOWLEDGMENTS}

Research supported by the Cashmere Goat Breeding Center of Liaoning Province, China. Research supported by grants from the Natural Science Foundation of China (\#308871792, \#30800807, \#31072097), Special Funds for Scientific Research on Public Causes (\#201303119), the Ministry of Science and Technology Support Program of China (\#2009BADA5B03), and the Special Financial Grant from the China Postdoctoral Science Foundation (\#20100471261, \#2013T60332).

\section{REFERENCES}

Alonso L and Fuchs E (2006). The hair cycle. J. Cell Sci. 119: 391-393.

Bai JY, Zhang Q, Li JQ, Dao EJ, et al. (2006). Estimates of genetic parameters and genetic trends for production traits of Inner Mongolian White Cashmere goat. Asian-Australas J. Anim. Sci. 19: 13-18.

Bai WL, Zhou CY, Ren Y, Yin RH, et al. (2011). Characterization of the GHR gene genetic variation in Chinese indigenous goat breeds. Mol. Biol. Rep. 38: 471-479.

Chase HB (1954). Growth of the hair. Physiol. Rev. 34: 113-126.

Cotsarelis G (2006). Epithelial stem cells: a folliculocentric view. J. Invest. Dermatol. 126: 1459-1468.

Fuchs E (2007). Scratching the surface of skin development. Nature 445: 834-842.

Fuchs E and Horsley V (2008). More than one way to skin. Genes Dev. 22: 976-985.

Fuchs E (2008). Skin stem cells: rising to the surface. J. Cell Biol. 180: 273-284.

Gebbie FE, Forsyth IA and Arendt J (1999). Effects of maintaining solstice light and temperature on reproductive activity, coat growth, plasma prolactin and melatonin in goats. J. Reprod. Fertil. 116: 25-33.

Ibraheem M, Galbraith H, Scaife J and Ewen S (1993). Growth and viability of secondary hair follicles of the Angora goat cultured in vitro. J. Anat. 182 (Pt 2): 231-238.

Jin M, Cui YH, Fu ZY, Gao WB, et al. (2006a). The correlation analysis of blood protein polymorphism with economic traits in Liaoning new-breeding cashmere goat. Yi Chuan 28: 529-532.

Jin M, Guo CL, Hu JH, Gao WB, et al. (2006b). Correlation analysis of economic traits in Liaoning new breed of cashmere goats using microsatellite DNA markers. Yi. Chuan Xue Bao 33: 230-235.

Li CQ, Yin J, Zhang YJ and Guo ZC (2005). Comparative study on skin and hair follicles cycling between Inner Mongolia and Liaoning Cashmere goats. Acta Vet. Zootech. Sin. 36: 674-679.

Palmer HG, Anjos-Afonso F, Carmeliet G, Takeda H, et al. (2008). The vitamin D receptor is a Wnt effector that controls hair follicle differentiation and specifies tumor type in adult epidermis. PLoS One 3: e1483.

Paus R, Muller-Rover S, Van Der Veen C, Maurer M, et al. (1999). A comprehensive guide for the recognition and classification of distinct stages of hair follicle morphogenesis. J. Invest. Dermatol. 113: 523-532.

Paus R and Foitzik K (2004). In search of the "hair cycle clock": a guided tour. Differentiation 72: 489-511.

Plikus MV, Mayer JA, de la Cruz D, Ruth EB, et al. (2008). Cyclic dermal BMP signalling regulates stem cell activation during hair regeneration. Nature 451: 340-344.

Qin F, Zhu X, Zhang W, Zhou J, et al. (2011). Effects of dietary iodine and selenium on nutrient digestibility, serum thyroid hormones, and antioxidant status of Liaoning cashmere goats. Biol. Trace Elem. Res. 143: 1480-1488.

Ryder ML (1987). Cashmere, Mohair and Other Luxury Animal Fibres for the Breeder and Spinner. 1-23.

Schmidt-Ullrich R and Paus R (2005). Molecular principles of hair follicle induction and morphogenesis. Bioessays 27: 247-261.

Schneider MR, Schmidt-Ullrich R and Paus R (2009). The hair follicle as a dynamic miniorgan. Curr. Biol. 19: R132-R142.

Schouwey K and Beermann F (2008). The Notch pathway: hair graying and pigment cell homeostasis. Histol. Histopathol. 23: 609-619.

Stenn KS and Paus R (2001). Controls of hair follicle cycling. Physiol. Rev. 81: 449-494. 
Wang X, Tredget EE and Wu Y (2012). Dynamic signals for hair follicle development and regeneration. Stem Cells Dev. 21: 7-18.

Zhang W, Wang RL, Zhu XP, Kleemann DO, et al. (2007). Effect of dietary copper on ruminal fermentation, nutrient digestibility and fiber characteristics in Cashmere goats. Asian -Australas J. Anim. Sci. 20: 1843-1848.

Zhang W, Zhang YS, Zhu XP, Wang RL, et al. (2011). Effect of different levels of copper and molybdenum supplements on performance, nutrient digestibility, and follicle characteristics in cashmere goats. Biol. Trace Elem. Res. 143: $1470-1479$. 